\title{
Relative Expression of SOX2 and OCT4 in Oral Squamous Cell Carcinoma and Oral Epithelial Dysplasia
}

\author{
Narges Ghazi ${ }^{1}$, Narges Aali ${ }^{2}$, Vahid-Reza Shahrokhi ${ }^{2}$, \\ Farnaz Mohajertehran*1,2 Nasrollah Saghravanian*2
}

\begin{abstract}
Background: Over $90 \%$ of oral cancers including oral squamous cell carcinoma (OSCC), originate from the oral cavity epithelium. Early detection for this lesion is as important. Evaluating cancer stem cell markers can improve the accuracy of early diagnosis, and be used as an OSCC prognostic indicator. We aimed to evaluate SOX2 and OCT4 gene expression among different grades of OSCC and oral epithelial dysplasia (OED) lesions.

Methods: Sixty samples that contains 45 OSCC and 15 OED samples were retrieved from the pathology department archives at the dental school of Mashhad. Demographic and pathological patient data including the tumor stage and tumor grade were assessed. Finally, SOX2 and OCT4 expression was examined using qRT-PCR.

Results: There was a significant difference in SOX2 and OCT4 expression between OSCC and OED samples ( $<<0.001$ ). The mean expression of SOX2 and OCT4 in OSCC samples were significantly higher than in the OED group ( $\mathrm{p}<0.001)$. The mean expression of SOX2 and OCT4 was higher in grade II and grade III OSCC compared to grade I. There was no significant relationship between the gene expression of SOX2 or OCT4 to the demographic, site and stage of tumors. The correlation between SOX2 and OCT4 expression $(\mathrm{p}=0.001)$ was significant in grade III OSCC specimens compared to other grades ( $\mathrm{p}=0.005, \mathrm{r}=0.68)$.

Conclusions: The increased expression of SOX2 and OCT4 in higher grades and the significant correlation of these genes with each other among OSCC specimens could suggest the role of SOX2 or OCT4 in oral mucosal carcinogenesis.
\end{abstract}

Keywords: OCT4, Oral Epithelial Dysplasia (OED), Oral Squamous Cell Carcinoma (OSCC), SOX2.

\section{Introduction}

Squamous cell carcinoma of oral cavity (OSCC) accounts for over $90 \%$ of oral neoplasms resulting in approximately 300,400 new cases, and, globally, a total of 145,400 cases result in mortality annually $(1,2)$. Majority of the oral and oropharyngeal tumors are OSCC, where some may arise from previous lesions called potentially malignant oral lesions (PMOLs). These lesions show oral epithelial dysplasia (OED) with an increased risk of malignant transformation rate (3-5).
Despite the recent advances in cancer therapies, the high rate of morbidity and mortality has not improved. High rate of mortality along with local recurrence, systemic metastasis or secondary tumors highlights the need for strategies focused on early detection $(4,5)$.

Some of accompanied tumor subpopulations cells display the increased tumorigenic properties. The presence of cancer stem cells (CSCs) was previously proven for several different 
malignancies including leukemia and breast cancer (6-9). Emerging CSCs reveal exciting new developments in molecular treatment modalities and conventional cancer treatments with promising alternative approaches $(8,9)$. Indeed, there have been many key CSC markers introduced that are involved in the progression and development of OSCC $(8,10)$. A recent report suggests the regulatory roles of CD133 (11) and CD44 (12) during self-renewal of squamous cell carcinoma and tumor progression. However, some studies discuss core transcription factors, sex-determining region Y-box 2 (SOX2) and organic cation/carnitine transporter4 (OCT4) as the prognostic squamous cell carcinoma markers in OSCC $(13,14)$. There was a reported significant association between the expression of OCT4 and SOX2 with the grade of OSCC $(13,14)$. Two key transcription factors involved in pluripotency of embryonic stem cells, regulating CSCs and the cellular reprogramming of somatic cells include OCT4 and SOX2 $(7,15,16)$. Initiation of cancer is the consequence of a multi-stage process during genetic changes, prior to the histopathological occurrence of cancer considering that these prior molecular changes could be discovered at the initial stages with normal histological features of tissues. Finding these key molecules could greatly enhance the early detection of OSCC $(7,9)$. Some studies, however, found that a significant difference could not be observed in the expression of SOX2 and CSC markers in the oral cavity and development of OSCC $(16,17)$. Further, few controversial studies report that there may be no association between OCT4 and SOX2 marker expression with histopathological grade, tumor stage and demographic characteristics including age and gender in OSCC patients. In the present study, we aimed to investigate the expression of OCT4 and SOX2 in OSCC tissue and OED specimens along with the demographic and pathological characteristics of the study population.

\section{Materials and methods Study Participants}

This observational-retrospective study was conducted on biopsy samples (OSCC tumor tissue and epithelial dysplastic tissue) taken from 60 patients who were identified from archives from the pathology department at the dental faculty of Mashhad University of Medical Sciences (MUMS). Laboratory analyses were performed in a molecular pathology and cytogenetic lab in the faculty of Medicine of MUMS. Demographic information of patients including age, sex and consumption of alcohol, smoke and drug were recorded. Based on collected records, information on the degree of tumor grade and stage of tumor were collected using checklists. Tissue samples were fixed in $10 \%$ formalin, followed by paraffin embedding. Tissue samples with $4 \mu \mathrm{m}$ of thickness were cut on a microtome for histopathological grading using routine hematoxylin and eosin $(\mathrm{H} \& \mathrm{E})$ staining. All protocols were approved by the ethics committee of MUMS.

\section{RNA extraction and cDNA synthesis}

MicroRNA (mRNA) was extracted from each sample for qualitative real-time polymerase chain reaction (qRT-PCR) to study the expression of OCT4 and SOX2 according to the manufacturer's protocol (High Pure RNA Paraffin Kit, FFPET RNA Tissue; Roche, Germany). Briefly, frozen tissue at $-80^{\circ} \mathrm{C}$ was cut using a sterile scalpel and transferred to a homogenizing tube containing $1 \mathrm{~mL}$ reagent of RiboPure Lysis Buffer (RLT). Following 10 seconds of shaking, the lysate was centrifuged $(2600 \mathrm{~g})$ for three minutes $\left(4^{\circ} \mathrm{C}\right)$ and the supernatant was subsequently transferred to a new tube containing one $\mathrm{mL}$ of $70 \%$ ethanol. Then, the mixture was passed through the RNeasy spin column followed by two washing steps (700 $\mu \mathrm{L}$ RW1 and $500 \mu \mathrm{L}$ of RPE buffer). Lastly, RNase-free water (30-50 $\mu \mathrm{L})$ was added to the spin column, followed by centrifugation, and the isolated RNA was frozen at $-80{ }^{\circ} \mathrm{C}$. To evaluate RNA quality, $1-2 \mu \mathrm{L}$ of the extracted RNA $18 \mathrm{~S}$ rRNA and $28 \mathrm{~S}$ rRNA was subjected to $1.5 \%$ agarose gel electrophoresis with $142 \mathrm{~V}$ voltage for 15 min and the 18S rRNA and 28S rRNA bands were visualized by ethidium bromide $(\mathrm{EtdBr})$ staining. The purity of the extracted RNA was determined using an absorbance ratio of 260 $\mathrm{nm} / 280 \mathrm{~nm}$ using a NanoDrop 1000 spectrophotometer (NanoDrop Technologies, Wilmington, Thermo, USA). Complementary DNA (cDNA) was synthesized by Thermo 
Scientific Revert Aid First Strand cDNA Synthesis Kit, Thermo Scientific, USA). Synthesis of cDNA was performed in $20 \mu \mathrm{L}$ containing 5x Reaction Buffer $(4 \mu \mathrm{L})$, Ribolock Rnase inhibitor $(1 \mu \mathrm{L})$, dNTP Mix $10 \mathrm{mMol}(2$ $\mu \mathrm{L})$ and Reverse Transcriptase $(1 \mu \mathrm{L})$ under ABI thermocycler (One Step, USA). The quality and concentration of the cDNAs were defined using a NanoDrop 1000 spectrophotometer (NanoDrop Technologies, Wilmington, DE, USA).

\section{Quantitative Real-time reverse transcription Polymerase Chain Reaction (QRT-PCR)}

Quantitative real-time PCR was conducted to quantitate the level of expression of OCT4 and SOX2 using a SYBR Green master mix kit (Thermos Scientific, Germany) on an ABI thermocycler (One Step, USA) with appropriate primers (Table 1). All reactions that were run in duplicate in separate wells contained a $20 \mu \mathrm{L}$ mixture that consisted of $0.6 \mu \mathrm{M}$ of each primer, $10 \mu \mathrm{M}$ SYBR Green master mix, $6.8 \mu \mathrm{M}$ diethyl pyrocarbonate (DEPC) water, and $2 \mu \mathrm{L}$ of DNA extract (concentration of $4 \mathrm{ng}$ ). The PCR program started with one cycle at $95{ }^{\circ} \mathrm{C}$ for ten minutes (Holding process), followed by 40 amplification cycles at $91^{\circ} \mathrm{C}$ for $35 \mathrm{~s}, 63^{\circ} \mathrm{C}$ for $35 \mathrm{~s}$, and $72{ }^{\circ} \mathrm{C}$ for $35 \mathrm{~s}$. A final amplification occurred under the following conditions: $72^{\circ} \mathrm{C}$ for $35 \mathrm{~s}$. Differential expression was analyzed using delta-delta comparative threshold $(\Delta \Delta \mathrm{CT})$ method. The housekeeping gene, Glyceraldehyde 3-phosphate dehydrogenase (GAPDH), was used as the reference gene $(18,19)$.

Table 1. Primers sequence genes.

\begin{tabular}{|c|c|c|}
\hline \multicolumn{2}{|c|}{ Gene } & \multirow{2}{*}{$\begin{array}{c}\text { Sequence 5' -3' (position) } \\
\text { 5'-TCG AGA ACC GAG TGA GAG G-3' } \\
\text { 5'-GAA CCA CAC TCG GAC CAC A -3' }\end{array}$} \\
\hline OCT4 & $\begin{array}{l}\text { Forward } \\
\text { Reverse }\end{array}$ & \\
\hline $\mathrm{SOX} 2$ & $\begin{array}{l}\text { Forward } \\
\text { Reverse }\end{array}$ & $\begin{array}{l}\text { 5'-TGA TGG AGA CGG AGC TGA A-3' } \\
\text { 5'-GGG CTG TTT TTC TGG TTG C-3' }\end{array}$ \\
\hline GAPDH & $\begin{array}{l}\text { Forward } \\
\text { Reverse }\end{array}$ & $\begin{array}{l}\text { 5'-CCC ATC ACC ATC TTC CAG G-3' } \\
\text { 5'-CAT CAC GCC ACA GTT TCC C-3' }\end{array}$ \\
\hline
\end{tabular}

\section{Statistical analysis}

The data was analyzed using software package for statistical analysis (SPSS) software version 20 (SPSS Inc., Chicago, IL, USA). Descriptive data including age and sex and mRNA expression of OCT4 and SOX2 were summarized as mean with the standard error of mean (SEM). First, normality of data was checked by One-Sample Kolmogorov-Smirnov test. Then mRNA expression of two investigated genes (OCT4 and SOX2) were compared in the tumoral and dysplastic tissues using an independent sample t-test. Evaluation of the level of OCT4 and SOX2 expression in tumor and dysplastic tissues and its relationship with clinicopathological parameters including tumor stage, and histological grade were assessed by one-way ANOVA. A Pearson's correlation coefficient test was used to investigate the correlation of OCT4 and SOX2 expression in tumors and dysplastic tissues to demographic information including age, gender and consumption of smoke, drug, and alcohol. A p- value less than 0.05 was considered statistically significant.

\section{Results \\ Patients and clinical characteristics}

This study was conducted on 60 samples including OSCC grade I (15 samples), OSCC grade II (15 samples), OSCC grade III (15 samples) and 15 OED samples. There were 33 females and 27 male patients with a mean age of $53.48 \pm 15.18$ years. The demographic characteristics of patients regarding OSCC and OED samples can be found in Table 2. There was no difference between the two studied groups related to age, gender and consumption of smoke, alcohol and drugs ( $p>0.05$ ). Lip and buccal mucosa was the most common primary tumor site (20 cases; 44.4\%), followed by gingiva (14 cases; $31.1 \%$ ) and mouth floor (11 cases; $24.4 \%)$. Regarding the clinical stage of OSCC, patients (20 cases; $44.4 \%$ ) were in early stage and advanced stages ( 25 cases; $55.6 \%$ ). 
Table 2. Demographic and Pathologic Information of OSCC Patients.

\begin{tabular}{|c|c|c|c|c|}
\hline Variables & & $\begin{array}{l}\text { OED patients } \\
\text { Number }(\%)\end{array}$ & $\begin{array}{l}\text { OSCC patients } \\
\text { Number }(\%)\end{array}$ & P-value \\
\hline \multirow{2}{*}{ Age } & $<60$ years & $7(46.7)$ & $30(66.7)$ & \multirow{2}{*}{0.14} \\
\hline & $>60$ years & $8(53.3)$ & $15(33.3)$ & \\
\hline \multirow{2}{*}{ Gender } & Female & $8(53.3)$ & $25(55.6)$ & \multirow{2}{*}{0.55} \\
\hline & Male & $7(46.7)$ & $20(44.4)$ & \\
\hline \multirow{2}{*}{ Smoking consumption } & No & $12(80)$ & $28(62.6)$ & \multirow{2}{*}{0.17} \\
\hline & Yes & $3(20)$ & $17(37.8)$ & \\
\hline \multirow{2}{*}{ Alcohol consumption } & No & $13(86.7)$ & $42(93.3)$ & \multirow{2}{*}{0.36} \\
\hline & Yes & $2(13.3)$ & $3(6.7)$ & \\
\hline \multirow{2}{*}{ Drug consumption } & No & $7(46.7)$ & $27(60)$ & \multirow{2}{*}{0.27} \\
\hline & Yes & $8(53.3)$ & $18(40)$ & \\
\hline
\end{tabular}

Squamous cell carcinoma of oral cavity (OSCC); Oral epithelial dysplasia (OED).

Expression of SOX2 and OCT4 markers in tumoral and dysplastic mucosa specimens

Table 3 describes the expression levels of SOX2 and OCT4 markers in OSCC tumoral and OED specimens. The results demonstrate that the expression of SOX2 $(p=0.001)$ was different when comparing OSCC and OED tissues (dysplastic mucosa). SOX2 expression was higher in tumor tissues compared to dysplastic mucosa specimens $(\mathrm{p}=0.001$, Table 3). Furthermore, qRT-PCR analysis on OCT4 expression in OSCC and OED samples tissues, revealed that there was a significant difference between these two groups, since the expression of OCT4 was significantly higher in tumor tissues compare to dysplastic mucosa specimens $(\mathrm{p}=0.001$, Table 3$)$.
When the association between SOX2 and OCT4 expression in OSCC and OED specimens was evaluated, we found that SOX2 expression did not correlate to the expression of OCT4 (Spearman's correlation test, $\mathrm{p}=0.001, \mathrm{r}=0.83$ ). The association between SOX2 or OCT4 expression and histopathological grade in OSCC samples was investigated using spearman's correlation test. The results illustrate that there was a significant correlation between OCT4 and SOX2 levels and grade III OSCC specimens (Spearman's correlation test, $\mathrm{p}=0.05, \mathrm{r}=0.68$ ). This correlation, however, was not significant for grade I (Spearman's correlation test, $\mathrm{P}=0.18, \mathrm{r}=$ 0.36 ) and grade II (Spearman's correlation test, $\mathrm{p}=$ $0.24, \mathrm{r}=0.32$ ).

Table 3. Expression level of two studied markers among OSCC and OED specimens based on QRT analysis.

\begin{tabular}{llll}
\hline Variables & $\begin{array}{l}\text { OED patients } \\
\text { Mean } \pm \text { SE }\end{array}$ & $\begin{array}{l}\text { OSCC patients } \\
\text { Mean } \pm \text { SE }\end{array}$ & P-value \\
\hline SOX2 Expression & $0.88 \pm 0.13$ & $5.24 \pm 0.52$ & $0.001^{*}$ \\
OCT4 Expression & $1.08 \pm 0.16$ & $5.61 \pm 0.55$ & $0.001^{*}$ \\
\hline
\end{tabular}

* $\mathrm{P}$ value less than 0.05 was considered as significant level. SE; standard error of mean, Squamous cell carcinoma of oral cavity (OSCC); Oral epithelial dysplasia (OED)

\section{Association of expression of CSC markers with} demographic and clinical characteristics SOX2 The relation of SOX2 expression with demographic and clinical characteristics between tumoral and dysplastic mucosa specimens was discussed in Table 4. In the OSCC tumor group, our analysis showed that there were significant differences between SOX2 expression and age. Younger patients $(<\quad 60$ years old $)$ had significantly higher SOX2 expression than older patients (> 60 years old) $(\mathrm{p}=0.005$, Table 4$)$. However, there were no differences between 
SOX 2 expression and age in the OED group $(\mathrm{p}=$ 0.93 ). In addition, there were no difference between gender and SOX2 expression in both groups (Table 4, p> 0.05). We evaluated the expression of SOX2 marker and the histopathological grade of tumors. Results illustrated that there was a significant difference among the OSCC grades $(\mathrm{p}=0.001)$. Patients with higher grade of OSCC (grade III) experienced higher SOX2 expression than cases with grade I and grade II respectively (Table 5). However, the analysis between SOX2 expression and the stage of tumors revealed that there was no significant difference between the tumor stage and SOX2 expression $(\mathrm{p}=0.90$; Table 5). Moreover, the relation between the site of OSCC tumors and SOX2 expression was not significant ( $p>0.05$; Table 5).

Table 4. Association of expression of SOX2 and OCT4 markers with demographic and pathological characteristics.

\begin{tabular}{|c|c|c|c|c|c|c|}
\hline Gene expression & Variables & & $\begin{array}{l}\text { OED tissue } \\
\text { Mean } \pm \text { SE }\end{array}$ & P-value & $\begin{array}{l}\text { OSCC tissue } \\
\text { Mean } \pm \text { SE }\end{array}$ & P-value \\
\hline \multirow{3}{*}{ SOX2 } & Age & $<60$ years & $0.86 \pm 0.19$ & \multirow[t]{2}{*}{0.93} & $6.03 \pm 0.73$ & $0.005 *$ \\
\hline & \multirow[b]{2}{*}{ Gender } & $\begin{array}{l}>60 \text { years } \\
\text { Female }\end{array}$ & $\begin{array}{l}0.89 \pm 0.19 \\
0.89 \pm 0.19\end{array}$ & & $\begin{array}{l}3.67 \pm 0.28 \\
5.66+0.81\end{array}$ & \multirow[b]{2}{*}{0.97} \\
\hline & & Male & $0.86 \pm 0.51$ & 0.70 & $4.72 \pm 0.59$ & \\
\hline \multirow{3}{*}{ OCT4 } & A oe & $<60$ years & $1.27 \pm 0.29$ & \multirow{2}{*}{0.30} & $6.27 \pm 0.77$ & \multirow{2}{*}{$0.03 *$} \\
\hline & Age & $>60$ years & $0.91 \pm 0.15$ & & $4.29 \pm 0.44$ & \\
\hline & Gender & $\begin{array}{l}\text { Female } \\
\text { Male }\end{array}$ & $\begin{array}{l}1.14 \pm 0.22 \\
1.01 \pm 0.23\end{array}$ & 0.91 & $\begin{array}{l}5.60 \pm 0.16 \\
5.63 \pm 0.64\end{array}$ & 0.37 \\
\hline
\end{tabular}

*P value less than 0.05 was considered as significant level. SE; standard error of mean, Squamous cell carcinoma of oral cavity (OSCC); Oral epithelial dysplasia (OED).

Table 5. Association of expression of SOX2 and OCT4 marker with pathological characteristics.

\begin{tabular}{|c|c|c|c|c|}
\hline Gene Expression & Variables & & $\begin{array}{l}\text { Gene expression } \\
\text { Mean } \pm \text { SE }\end{array}$ & P-value \\
\hline \multirow{8}{*}{ SOX2 } & \multirow{3}{*}{ Grade } & I & $3.16 \pm 1.13$ & \multirow{3}{*}{$0.001 *$} \\
\hline & & II & $4.53 \pm 2.17$ & \\
\hline & & III & $8.04 \pm 4.35$ & \\
\hline & \multirow{2}{*}{ Stage } & Early stage & $5.17 \pm 1.02$ & \multirow{3}{*}{0.90} \\
\hline & & Advance stage & $5.30 \pm 0.48$ & \\
\hline & \multirow{3}{*}{ Site } & Lips \& buccal mucosa & $5.82 \pm 0.74$ & \\
\hline & & Gingivae & $4.14 \pm 0.66$ & \multirow{2}{*}{0.37} \\
\hline & & Mouth floor & $5.60 \pm 1.42$ & \\
\hline \multirow{8}{*}{ OCT4 } & \multirow{3}{*}{ Grade } & $\mathrm{I}$ & $3.46 \pm 0.94$ & \multirow{3}{*}{$0.001 *$} \\
\hline & & II & $4.47 \pm 1.76$ & \\
\hline & & III & $8.90 \pm 4.61$ & \\
\hline & \multirow{2}{*}{ Stage } & Early stage & $5.73 \pm 1.05$ & \multirow{3}{*}{0.84} \\
\hline & & Advance stage & $5.52 \pm 0.54$ & \\
\hline & \multirow{3}{*}{ Site } & Lips \& buccal mucosa & $6.56 \pm 0.83$ & \\
\hline & & Gingivae & $4.30 \pm 0.64$ & \multirow{2}{*}{0.22} \\
\hline & & Mouth floor & $5.56 \pm 1.42$ & \\
\hline
\end{tabular}

*P value less than 0.05 was considered as significant level. SE; standard error of mean, Squamous cell carcinoma of oral cavity (OSCC); Oral epithelial dysplasia (OED).

\section{OCT4}

The relation of OCT4 expression with demographic and clinical characteristics of OSCC specimens and dysplastic mucosa specimens was presented in Table 4. Similar to SOX2 expression, there were significant differences between OCT4 expression and age in the OSCC tumor group. The younger patients ( $<60$ years old) had a significantly higher OCT4 expression than older patients (> 60 years old) $(\mathrm{p}=0.032$, Table 4$)$. However, there was no difference between OCT4 
expression and age in the OED group $(\mathrm{p}=0.30)$. Further, there were no differences between gender and OCT4 expression in both groups (Table 4, p> 0.05). Analysis related to the expression of the OCT4 marker with histopathological grade of tumors revealed that there was a significant difference among the different OSCC grades $(\mathrm{p}=$ 0.001). Patients with a higher grade of OSCC (grade III) had significantly higher OCT4 expressions than studied cases with grade I and grade II respectively (Table 5). This point was accredited to the relation of OCT4 expression and stage of tumors, however, this relation was not significant $(\mathrm{p}=0.84$; Table 5). Moreover, relation between the site of OSCC tumors and OCT4 expression were not statistically significant ( $\mathrm{p}>$ 0.05; Table 5).

\section{Discussion}

While the cancer stem cell theory has been proven for different cancers, more research is required to investigate the role of CSCs in the development and progression of OSCC $(20,21)$. Several researchers have focused on studying the expression of key CSC transcription factors including SOX2 and OCT4 in normal oral mucosa and OSCC. Normal cells in sever stages are transformed progressively to cancer cells. Previous studies revealed that the expression of CSC markers have increased in normal tissue adjacent to tumoral and pre-neoplastic tissues, which indicate early molecular changes in normal tumor-adjacent cells and the possible role of CSCs in the process of carcinogenesis (12). Tracing the involved key stem cell markers could, therefore, enhance the accuracy of OSCC diagnosis even in the early stages.

SOX2 as a transcription factor in pluripotency and self-renewal of embryonic stem cells plays a key role in the survival of malignant squamous cell against apoptosis (22). Our results showed increased expression of SOX2 in OSCC tumoral tissue compared to dysplastic epithelium. An investigation led by Verma et al., found that 60 cases of oral epithelial dysplasia showed that an alteration in SOX2 is likely an important event in head and neck carcinogenesis (23). To assess the risk of malignant transformation, they concluded that SOX2 expression could be valuable in cases of oral epithelial dysplasia. There are controversies regarding the expression of SOX2 and its clinical usefulness between several studies involving OSCC. Naini et al (17) showed increased expression of SOX2 in adjacent nontumoral tissue compared to tumoral tissue. In addition, simultaneous expressions of OCT4 and SOX2 were evaluated in rat models as well as pre-neoplastic and neoplastic human tissue samples. The results showed that the expression of these two markers in metastatic samples was lower than that in the primary tumor sites (24). The study by Fu et al., showed that 436 tumoral samples, containing 362 adjacent non-tumoral and 76 normal tissue samples found that the expression of SOX2 was higher in the adjacent non-tumoral tissue compared to tumoral tissues (16). Also, the high expression of SOX2 was found in normal bronchial mucosa compared to squamous dysplasia of the lungs (25). In 2019, de Vicente et al, investigated the clinical relevance of SOX2 protein expression in early stages of OSCC (55 cases with oral epithelial dysplasia) by immunohistochemistry analysis, and its impact on prognosis and disease outcome at late stages (125 patients with OSCC). They found that there was nuclear SOX2 expression in $49(39 \%)$ OSCC cases, with more frequency in early tumor stages and N0 cases and was associated to increased survival. Similar to our study, they found that a significant correlation between the histopathological grade and SOX2 expression (26). They concluded that SOX2 expression emerges as an independent OSCC predictor risk in patients with oral leukoplakia. Additionally, Huang et al. investigated the expression of SOX2 and OCT 4 and the prognosis of tongue squamous cell carcinoma (66 TCC tissue samples) by immunohistochemistry analysis and found the similar results. They concluded that the correlation of both markers was observed in TSCC, and the expression of SOX2 could be used as a prognostic indicator of TSCC (27). However, the results on SOX2 expression are controversial, as González-Márquez et al (28) found that SOX2 expression did not correlate to disease stage, tumor grade or $\mathrm{N}$ classification, lymph node metastasis, recurrence or clinical 
outcome. They concluded that SOX2 expression is a common event in hypopharynx and larynx, but not in sinonasal squamous cell carcinoma (SCC). The absence of a correlation to clinical outcome may suggest a role for SOX2 in tumor initiation, but not in tumor progression. In the present study, we found that there was no significant difference between expression of SOX2 or OCT4 and site of studied tumors. Comparatively, Neumann et al. showed that higher expression of SOX2 at the site of primary tumor correlated with poorer prognosis and lymph node metastasis (29).

Another investigated transcription factor is OCT4, the key CSC marker involved in the maintenance of pluripotency and self-renewal in undifferentiated embryonic stem (ES) cells (30). This marker could reprogram human somatic fibroblasts into embryonic stem cell-like pluripotent cells (PSC) (31). OCT4O is upregulated in OSCC-CSCs but its molecular mechanisms in OSCC remain to be elucidated. A previous study suggests that Oct4-mediated tumorigenicity is associated with the regulation of epithelial-mesenchymal transition (32). In agreement with our study, Vaiphei et al., a study on esophageal SCC, showed increased expression of OCT4 in the esophageal mucosa adjacent to an area of mild dysplasia and basal hyperplasia (13).

To the best of our knowledge, this study is the first one to measure CSCs markers including

\section{References}

1. Siegel RL, Miller KD, Jemal A. Cancer statistics, 2019. CA Cancer J Clin. 2019;69(1):7-34.

2. Bray F, Ferlay J, Soerjomataram I, Siegel RL, Torre LA, Jemal A. Global cancer statistics 2018: GLOBOCAN estimates of incidence and mortality worldwide for 36 cancers in 185 countries. CA Cancer J Clin. 2018;68(6):394-424.

3. Liu SA, Wong YK, Lin JC, Poon CK, Tung $\mathrm{KC}$, Tsai WC. Impact of recurrence interval on survival of oral cavity squamous cell carcinoma patients after local relapse. Otolaryngol Head Neck Surg. 2007;136(1):112-8. both SOX2 and OCT4 at the RNA level. The presence of non-OSCC specimens in dysplastic specimens along with OSCC specimens with different histopathological grade was another novel area of study. Future studies may be required to elucidate the association of prognosis, tumorigenicity and survival rate with the expression of CSCs markers. Despite several study limitations, we found that the expression of SOX2 and OCT4 was significantly higher in OSCC tumor tissue compared to OED specimens. However, this difference was also linked to histopathological grade, since patients with higher development in grade III were experienced higher expression levels of both SOX2 and OCT4 than patients with lower grade. Based our findings, we concluded that increased expression of SOX2 and OCT4 from dysplastic mucosa to squamous cell carcinoma could suggest the probable role of these genes during the process of oral mucosal carcinogenesis. Overall, increasing the grade of the squamous cell carcinoma and reducing cellular differentiation led to the increased the expression of these genes.

\section{Acknowledgment}

The authors appreciate the Research Council of Mashhad University of Medical Sciences, Faculty of dentistry for their financial support under two-thesis numbers 970219 and 961396.

The authors declare that there are no conflicts of interest.

4. Sharma P, Saxena S, Aggarwal P. Trends in the epidemiology of oral squamous cell carcinoma in Western UP: an institutional study. Indian J Dent Res. 2010;21(3):316-9.

5. Woolgar JA, Scott J, Vaughan E, Brown J, West C, Rogers S. Survival, metastasis and recurrence of oral cancer in relation to pathological features. Annals of the Royal College of Surgeons of England. 1995;77(5):325.

6. Fillmore CM, Kuperwasser C. Human breast cancer cell lines contain stem-like cells that selfrenew, give rise to phenotypically diverse progeny and survive chemotherapy. Breast Cancer Res. 2008;10(2):R25. 
7. Islam F, Qiao B, Smith RA, Gopalan V, Lam AK-Y. Cancer stem cell: fundamental experimental pathological concepts and updates. Exp Mol Pathol. 2015;98(2):184-91.

8. Al-Hajj M, Clarke MF. Self-renewal and solid tumor stem cells. Oncogene. 2004;23(43):7274-82. 9. Allegra A, Alonci A, Penna G, Innao V, Gerace D, Rotondo F, et al. The cancer stem cell hypothesis: a guide to potential molecular targets. Cancer Invest. 2014;32(9):470-95.

10. Reya T, Morrison SJ, Clarke MF, Weissman IL. Stem cells, cancer, and cancer stem cells. nature. 2001;414(6859):105-11.

11. $\mathrm{Yu} \mathrm{CC}, \mathrm{Hu} \mathrm{FW}, \mathrm{Yu} \mathrm{CH}$, Chou MY. Targeting CD133 in the enhancement of chemosensitivity in oral squamous cell carcinoma-derived side population cancer stem cells. Head \& neck. 2016;38(S1):E231-E8.

12. Krishnamurthy S, Nor J. Head and neck cancer stem cells. Journal List. 2012;91(4):334-340.

13. Vaiphei K, Sinha SK, Kochhar R. Comparative analysis of Oct4 in different histological subtypes of esophageal squamous cell carcinomas in different clinical conditions. Asian Pac J Cancer Prev. 2014;15(8):3519-24.

14. Li Y, Lv Z, He G, Wang J, Zhang X, Lu G, et al. The SOX17/miR-371-5p/SOX2 axis inhibits EMT, stem cell properties and metastasis in colorectal cancer. Oncotarget. 2015;6(11):9099-112.

15. Ren ZH, Zhang CP, Ji T. Expression of SOX2 in oral squamous cell carcinoma and the association with lymph node metastasis. Oncol lett. 2016;11(3):1973-1979.

16. Fu TY, Hsieh IC, Cheng JT, Tsai MH, Hou YY, Lee JH, et al. Association of OCT 4, SOX 2 , and NANOG expression with oral squamous cell carcinoma progression. J Oral Pathol Med. 2016;45(2):89-95.

17. Baghai Naini F, Aminishakib P, Abdollahi A, Hodjat M, Mohammadpour H, Kardouni Khoozestani N. Relative Expression of OCT4, SOX2 and NANOG in Oral Squamous Cell Carcinoma Versus Adjacent Non-Tumor Tissue. Asian Pac J Cancer Prev. 2019;20(6):1649-1654. 18. Mohtasham N, Ayatollahi H, Saghravanian N, Zare R, Shakeri M, Sahebkar A, et al. Evaluation of Tissue and Serum Expression
Levels of Lactate Dehydrogenase Isoenzymes in Patients with Head and Neck Squamous Cell Carcinoma. Anticancer Agents Med Chem. 2019;19(17):2072-2078.

19. Mohajertehran F, Ayatollahi H, Jafarian AH, Khazaeni K, Soukhtanloo M, Shakeri M-T, et al. Overexpression of Lactate Dehydrogenase in the Saliva and Tissues of Patients with Head and Neck Squamous Cell Carcinoma. Rep Biochem Mol Biol. 2019;7(2):142-149.

20. Griffin JD, Lowenberg B. Clonogenic cells in acute myeloblastic leukemia. Blood. 1986;68(6):1185-95.

21. Aktas B, Tewes M, Fehm T, Hauch S, Kimmig R, Kasimir-Bauer S. Stem cell and epithelial-mesenchymal transition markers are frequently overexpressed in circulating tumor cells of metastatic breast cancer patients. Breast Cancer Res. 2009;11(4):R46.

22. Hussenet $\mathrm{T}$, du Manoir S. SOX2 in squamous cell carcinoma: amplifying a pleiotropic oncogene along carcinogenesis. Cell Cycle. 2010;9(8):1480-6.

23. Verma V, Chandrashekar C. Evaluation of SOX2 and podoplanin expression in oral epithelial dysplasia and its correlation with malignant transformation. Journal of investigative and clinical dentistry. 2019;10(4):e12450.

24. Qiao B, He B, Cai J, Yang W. The expression profile of Oct4 and Sox 2 in the carcinogenesis of oral mucosa. Int J Clin Exp Pathol. 2014;7(1):28-37.

25. Yuan P, Kadara H, Behrens C, Tang X, Woods D, Solis LM, et al. Sex determining region Y-Box 2 (SOX2) is a potential celllineage gene highly expressed in the pathogenesis of squamous cell carcinomas of the lung. PloS one. 2010;5(2):e9112.

26. de Vicente JC, Donate-Pérez del Molino P, Rodrigo JP, Allonca E, Hermida-Prado F, Granda-Díaz R, et al. SOX2 Expression Is an Independent Predictor of Oral Cancer Progression. J Clin Med. 2019;8(10):1744.

27. Huang CF, Xu XR, Wu TF, Sun ZJ, Zhang WF. Correlation of ALDH 1, CD 44, OCT 4 and SOX 2 in tongue squamous cell carcinoma and their association with disease progression and prognosis. J Oral Pathol Med. 2014;43(7):492-8. 
28. González-Márquez R, Llorente JL, Rodrigo JP, García-Pedrero JM, Álvarez-Marcos C, Suárez C, et al. SOX2 expression in hypopharyngeal, laryngeal, and sinonasal squamous cell carcinoma. Human pathology. 2014;45(4):851-7.

29. Neumann J, Bahr F, Horst D, Kriegl L, Engel $\mathrm{J}$, Mejías-Luque R, et al. SOX2 expression correlates with lymph-node metastases and distant spread in right-sided colon cancer. BMC cancer. 2011;11:518.

30. Wang J, Rao S, Chu J, Shen X, Levasseur
DN, Theunissen TW, et al. A protein interaction network for pluripotency of embryonic stem cells. Nature. 2006;444(7117):364-8.

31. Park I-H, Zhao R, West JA, Yabuuchi A, Huo $\mathrm{H}$, Ince $\mathrm{TA}$, et al. Reprogramming of human somatic cells to pluripotency with defined factors. nature. 2008;451(7175):141-6.

32. Tsai L-L, Hu F-W, Lee S-S, Yu C-H, Yu C$\mathrm{C}$, Chang Y-C. Oct4 mediates tumor initiating properties in oral squamous cell carcinomas through the regulation of epithelial-mesenchymal transition. PloS one. 2014;9(1):e87207. 